\title{
Correction to: Detecting neural assemblies in calcium imaging data
}

Jan Mölter ${ }^{1,2}$, Lilach Avitan ${ }^{1}$ and Geoffrey J. Goodhill ${ }^{1,2^{*}}$

\section{Correction to: BMC Biol}

https://doi.org/10.1186/s12915-018-0606-4

Upon publication of the original article, [1], the authors noticed that the first authors' affiliation contained an error. In the first affiliation it reads "Queensland Brian Institute", whereas it should in fact be "Queensland Brain Institute".

Received: 15 February 2019 Accepted: 15 February 2019

Published online: 06 March 2019

\section{Reference}

1. Mölter J, Avitan L, Goodhill GJ. Detecting neural assemblies in calcium imaging data. BMC Biol. 2018;16:143. https://doi.org/10.1186/s12915-018-0606-4.

\footnotetext{
* Correspondence: g.goodhill@uq.edu.au

${ }^{1}$ Queensland Brain Institute, The University of Queensland, Brisbane 4072 Australia

${ }^{2}$ School of Mathematics and Physics, The University of Queensland, Brisbane 4072, Australia
} 